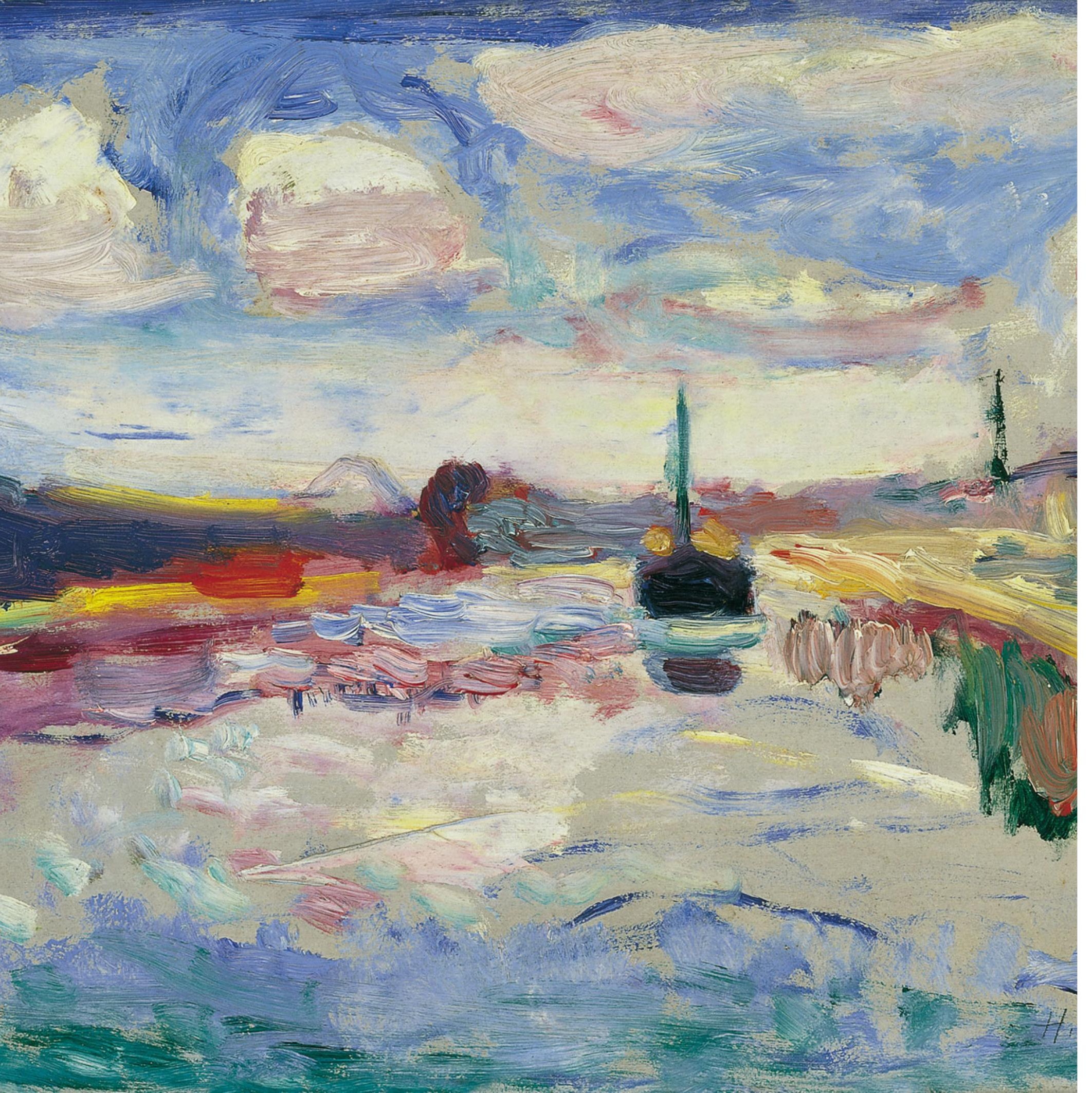




\section{EL CANAL DU MIDI, EN BUSCA DE UN PROYECTO PATRIMONIAL Y PAISAJÍSTICO}

\section{Paula Orduña Giró}

Geógrafa. Máster en Investigación en Urbanismo

Director: Joaquin Sabaté Bel

Departamento de Urbanismo y Ordenación del Territorio (DUOT) UPC

\section{RESUMEN}

El Canal du Midi constituye un eje que atraviesa el sur de Francia, uniendo el océano Atlántico con el mar Mediterráneo. Desde 1996 está catalogado como patrimonio mundial por la Unesco. El artículo analiza el cambio de función y de usos de un canal donde, además de la función agrícola, a lo largo del siglo XX, se ha pasado del transporte comercial de mercancías al uso turístico y deportivo. Nos interesa examinar cómo se gestiona el valor patrimonial de esta obra de ingeniería hidráulica, así como los discursos, proyectos e instrumentos que han propiciado una nueva puesta en valor.

Palabras clave: Obra de ingeniería hidráulica, eje patrimonial, mutación de usos, gestión del patrimonio. 


\section{ID_INVESTIGACIONES}

\section{ABSTRACT}

The Canal du Midi is an axis passing through the south of France, connecting the Atlantic Ocean with the Mediterranean Sea. Since 1996 it has been included in the World Heritage List by UNESCO. This article analyzes the changing role and uses of an hydraulic engineering project where, as well as its agricultural function, throughout the twentieth century it has also been used for the commercial transportation of goods and for tourist and sporting use. We are interested in examining how the heritage value of this hydraulic engineering work is managed, as well as the discourses, projects and instruments which have led to these new enhancements.

Key words: Hydraulic engineering project, heritage axis, change of uses, heritage management.

En la página anterior: Canal du Midi, Henri Matisse (1898). Colección Carmen Thyssen-Bornemisza en depósito en el Museo Thyssen-Bornemisza. Fuente: http://www.museothyssen.org/ 
Localización del Canal du Midi. Fuente: elaboración propia a partir de [Haute-Garonne 2008] y aspecto actual. Fuente: www.vnf.fr
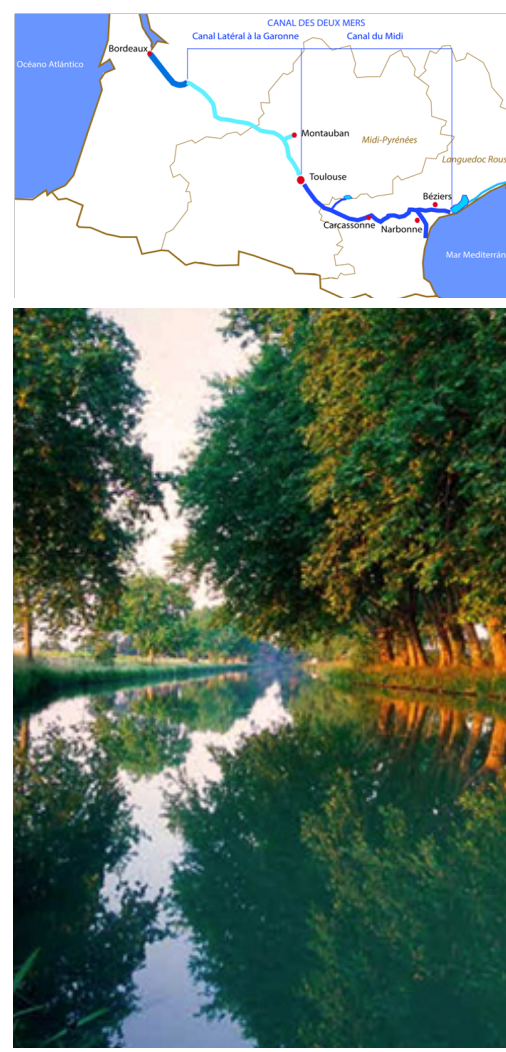

\section{INTRODUCCIÓN}

Nuestro objetivo es estudiar cómo se han transformado los valores asociados al Canal du Midi y cómo el valor patrimonial de una compleja obra hidráulica del pasado que ha caracterizado la región, permite sustentar más tarde un paisaje cultural basado en el agua como elemento dominante. Nos interesa discernir cómo se gesta la puesta en valor de esta infraestructura, siguiendo los pasos que van desde el declive del transporte comercial hasta su incorporación a la Lista de Patrimonio Mundial de la Unesco, en 1996. Analizaremos las tensiones surgidas entre las funciones originales y las que se desprenden del turismo y el uso deportivo, observando para ello los proyectos de ordenación y gestión existentes. Finalmente, a través de un anteproyecto de gestión reciente, valoraremos las potencialidades y problemáticas de este eje, tratando de determinar también, a partir de los usos y actividades actuales, qué habría de auténtico y qué de artificial en la puesta en valor de este curso de agua artificial. Por auténtica, entendemos una iniciativa que surge de las propias necesidades del territorio, y que incorpora, por tanto, diversos niveles de contraste. Por artificial, en cambio, entendemos una iniciativa de carácter menos permeable que no capta con agilidad las necesidades del entorno y se muestra poco flexible.

Introduciremos brevemente la historia y el contexto del Canal du Midi. Nos centraremos después en el momento en el que se inicia la decantación hacia unos nuevos usos y valores del Canal, resaltando las tensiones que ello acarrea entre los defensores de la modernización y los paladines de su puesta en valor patrimonial. Seguidamente, nos centraremos en el discurso que sustenta su puesta en valor.

En el cuarto apartado analizaremos los documentos encontrados relativos al proyecto territorial y paisajístico patrimonial. Entre los más destacados cabe citar el informe de 2003 (Rapport Chassel 2003), el informe de la Unesco de 2005 (Unesco 2005), el anteproyecto paisajístico de 2007 (Résumé Charte Interservices 2007), el Contrato regional específico de 2008 (Contrat Rég. 2008), el esquema de coherencia territorial del Pays Lauragais (SCOT 2012), un informe de 2012 (Canal Péril 2012) y un segundo informe del mismo año (Rapport Mission 2012). Prestaremos especial atención al anteproyecto de carácter paisajístico o Résumé Charte Interservices de 2007. En el quinto y último apartado, aumentaremos la escala de análisis y nos centraremos en los usos actuales del espacio y en las intervenciones a escala local y edificatoria (5). Esto nos permitirá concluir contestando a la pregunta planteada respecto a lo auténtico y participativo o lo artificial de la puesta en valor del Canal du Midi. 


\section{PRESENTACIÓN HISTÓRICA DEL CANAL}

El Canal de los dos Mares (Canal des Deux-mers) es una obra de ingeniería hidráulica de $360 \mathrm{~km}$ que une el océano Atlántico y el mar Mediterráneo. Se divide en dos vertientes según su adscripción geográfica (atlántica o mediterránea). Las secciones orientales forman lo que estrictamente se denomina el Canal du Midi o del Languedoc. Esta vertiente mediterránea comprende 240 km entre Montagne Noire y Sète y corresponde a una construcción anterior a la de la vertiente atlántica.

El canal constituye un eje que atraviesa buena parte del Sur de Francia, cruzando 104 municipios encuadrados en cuatro de los 95 departamentos (Haute-Garonne, Tarn, Aude, Hérault) de la Francia continental y en dos de sus 21 regiones (Midi-Pyrénées y Languedoc-Roussillon). El proyecto de abrir una vía que una el Atlántico con el Mediterráneo con objeto de evitar el rodeo de la Península Ibérica existe desde tiempos romanos (Fiche 2007). En el siglo XVI vuelve a plantearse su construcción entre el Oeste y el Este del reino. Sin embargo, la obra no se lleva a cabo hasta el siglo XVII, una vez que se estabiliza la situación política del país y de la zona.

Bajo el reinado de Luís XIV, en 1662, el ingeniero Pierre Paul Riquet propone el proyecto al ministro Colbert. El reinado del Rey Sol se considera una de las etapas más señaladas de la historia francesa. El triunfo de una monarquía absoluta y centralizada en la corte de Versalles constituye el paradigma de monarquía absolutista europea, ilustrada por la frase atribuida a Luís XIV “L'État, c'est moi”.
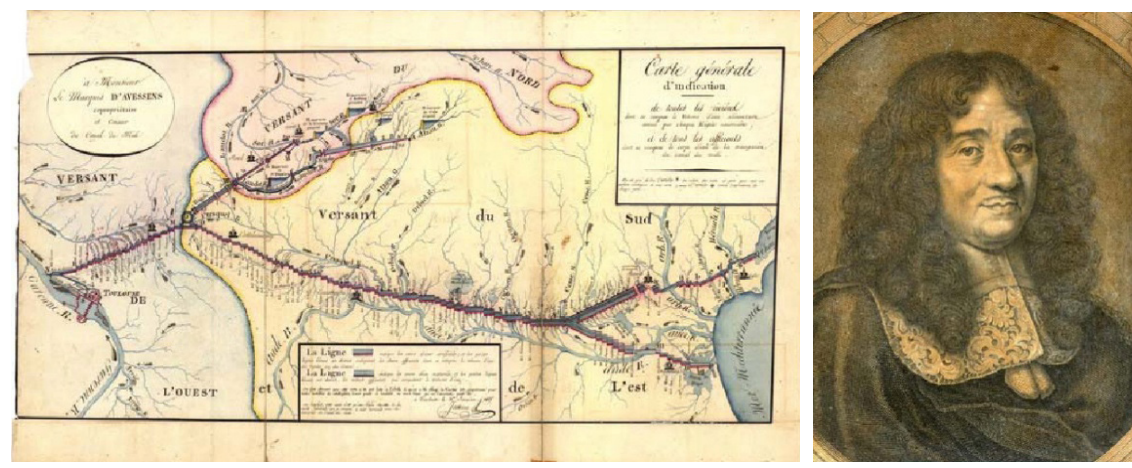

Plano de la obra y retrato del ingeniero Pierre-Paul Riquet. Fuente: (Rapport Mission 2012) 
Las obras se llevan a cabo en catorce años, entre 1667 y 1681, gracias al trabajo de 12.000 obreros. El dispositivo hidráulico se perfecciona a partir de 1686 con la construcción de unos acueductos ideados por Vauban, un notable experto en construcción de fortificaciones. Entre 1730 y 1820 se realizan las plantaciones más importantes en sus riberas. Originalmente los agricultores plantan moreras, de acuerdo con sus preferencias. A partir de 1770 , se le encomienda a un experto en jardinería que diversifique las plantaciones, pasándose así a repoblar las orillas con álamos, sauces, chopos, olmos, fresnos e incluso robles y pinos marítimos. En 1820 se inicia la plantación masiva de plátanos, pues su madera es apreciada y sus raíces estabilizan los taludes. En 1856 concluye la ampliación del Canal hacia Poniente con la apertura del canal lateral del Garona. Además de su función como infraestructura de comunicación entre el Atlántico y el Mediterráneo, el Canal llega a desempeñar un papel excepcional en el desarrollo de la pujante agricultura del Sur de Francia.

A mediados del siglo XIX, el transporte de mercancías por el Canal alcanza sus cotas más altas. A partir de entonces, sin embargo, se acusa la competencia del ferrocarril, que se acentúa por la circunstancia de que la Compañía de Ferrocarriles del Midi concierta un contrato de arrendamiento de 40 años sobre el Canal. La competencia del nuevo sistema de transporte y la falta de mantenimiento por parte de la Compañía, significan el principio del fin del transporte por el Canal du Midi (Résumé Charte Interservices 2007).

Según Adgé (1992), la obra marca el inicio de la Edad Moderna en la construcción de vías navegables. "Constituye una de las realizaciones del genio civil más extraordinarias de la era moderna que abre la puerta a la revolución industrial”"1 (Adgé 1992). Más allá de la pericia técnica que requiere el caso, el proyecto significa la culminación de una larga maduración de movimientos intelectuales y científicos de la época.

El Canal supone hitos técnicos y sociales entre como:

- su condición de medio estratégico de comunicación;

- el impacto sobre los usos agrícolas y el paisaje de la zona gracias a la irrigación;

- su contribución al desarrollo de una identidad cultural propia, representada por los navegantes fluviales (batellerie): la "Gente del agua” (Gens de l'eau) (Adgé 1992; Unesco 1996);

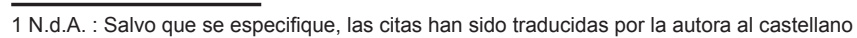


- su incorporación armoniosa al territorio, a pesar de la interrupción de la trama viaria que pudo suponer en el momento de su construcción, subsanada luego por más de un centenar de puentes.

Si bien el impacto directo sobre el paisaje aparentemente se reduce a una franja de una decena de metros a lo largo del recorrido, con el paso del tiempo, ha supuesto la consolidación de una trama verde que se adapta al relieve sin dejar de ser una obra técnica.

Además, cabe precisar que después de Rusia, Francia es el país europeo con la red fluvial más extensa. Cuenta con $8.800 \mathrm{~km}$ de ríos y canales navegables, aunque la cifra ha disminuido considerablemente desde $1975^{2}$.

\section{LA DISYUNTIVA ENTRE MODERNIZACIÓN Y VALORIZACIÓN PATRIMONIAL}

Las tensiones entre la función mercantil y la patrimonial del Canal constituyen una constante desde principios del siglo XX hasta el declive absoluto de su cometido como corredor de transporte mercantil. La opción de modernizar las vías navegables, imprescindible para preservar la competitividad económica del Canal, choca, hasta los años 1970, con la puesta en valor del interés cultural y patrimonial de la obra hidráulica, criterio que finalmente se acaba imponiendo.

Entre 1681 y 1930 las gabarras mercantiles son las embarcaciones predominantes. Sus tripulantes (bateliers) mantienen un modo de vida estrechamente vinculado a su trabajo, resultante al final de una tradición de tres siglos. En tanto que trabajadores, forman la corporación de la "Gente del agua", (Gens de l'eau) (Bouneau y Lung 2006) puesto que su estilo de vida se desarrolla en un mundo cerrado, al margen de la gente de tierra.

A lo largo de esos tres siglos, el auge funcional del transporte mercantil por el Canal du Midi se sitúa a principios del siglo XIX. En 1858 tras la firma del convenio de cesión a la Compañía de Ferrocarriles del Midi se encarecen los peajes y se convierte en la vía fluvial más cara de Francia. En 1897 se traspasa la vía al Estado, que lo subvenciona para hacerlo más competitivo, suprimiendo las tasas y reactivando el tráfico mercantil. Sin embargo, la competencia con el tren resulta ya insuperable para el transporte fluvial. Un motivo añadido

2 Fecha en la que se contabilizaban hasta $12.500 \mathrm{~km}$ [Peniche 2013].
Antiguas postales del Canal du Midi, puerto de Carcassonne s.XIX Fuente: www.canalmidi.com

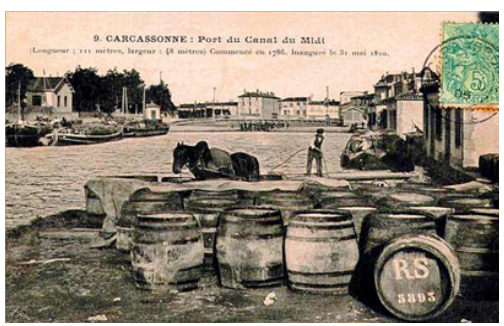



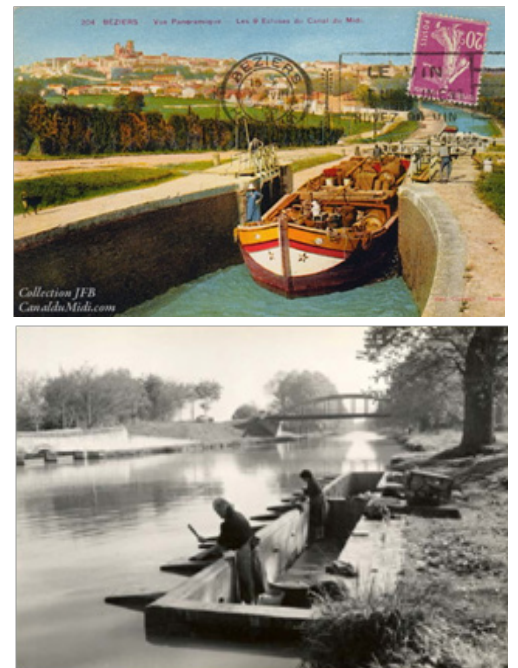

"Gens de l'eau" y otras actividades vinculadas a Canal du Midi. Fuente: www.phytolab.fr y www. sudouest.vnf.fr que entorpece el transporte de mercancías por el Canal son las limitaciones de su batimetría. No soporta grandes tonelajes debido a su escasa profundidad (Rapport Chassel 2003).

A principios del siglo XX se desarrollan los primeros debates sobre la necesidad de modernizar la infraestructura y favorecer la competitividad. Pero pronto algunas voces se levantan en contra de la ejecución de la ley-programa Freycinet sobre gálibo (1879). Se oponen a la modernización técnica, pues transformaría los vestigios, ocultando el interés patrimonial de la obra de Pierre-Paul Riquet. Entre las voces críticas destaca la del Touring Club France, asociación activa entre 1890 y 1983 dedicada a la promoción del turismo en general, y en particular a la protección del patrimonio fluvial (Rapport Mission 2012).

Paralelamente cabe destacar el fuerte sentimiento de identidad de la región del Midi Pyrénées y más específicamente de la "Gente del agua" que consideran el Canal "como su feudo" y como un patrimonio que deben defender "frente a los extraños" (Bouneau et Lung 2006). En este contexto, los usos lúdicos y turísticos, ajenos a la función primigenia, se perciben como frivolidades, e incluso como agresiones, que deben ser desenmascaradas (Bouneau et Lung 2006).

En medio del choque cultural que tiene lugar entre los sectores que viven el ámbito del Canal como medio de subsistencia y quienes lo perciben o utilizan como área de uso potencialmente recreativo, se produce una expansión de la motorización de las embarcaciones que favorece la función recreativa del canal. La motorización sistemática sobreviene entre 1921 y 1936. Gracias a ella se liberan las vías de servicio de las orillas facilitando así su uso por parte de paseantes y ciclistas. En 1951 aparecen las primeras embarcaciones de recreo en Béziers (Bouneau et Lung 2006). Mientras, la explotación comercial del canal se ve cada vez más limitada por las restricciones de tonelaje y el límite del gálibo. Para el transporte fluvial esta restricción es, si cabe, aún más perjudicial que para otros modos de transporte, ya que su competitividad aumenta en relación directa con el tonelaje transportado.

Ante tales contrariedades el turismo fluvial y la función recreativa concurren como una nueva forma de explotación económica del canal, en sintonía además con el desarrollo de la cultura del ocio, característica del mundo occidental. No obstante, según Bouneau y Lung (2006) la consolidación de la explotación turística es un proceso lento y controvertido porque tanto los actores locales como los institucionales lo perciben como la última solución, legítima sólo cuando hubiesen fracasado todas las posibilidades en términos de ordenación y desarrollo económico. 
El tráfico de mercancías inicia su declive definitivo en los años 1970, de modo que en los años ochenta tan solo quedan dos gabarras de transporte regular (Rapport Mission 2012). La disminución del tráfico comercial, junto al advenimiento de una sociedad proclive al ocio y en la cual se valoran cada vez más los espacios naturales que procuren momentos de distensión y de evasión de la vida cotidiana, hacen que el paisaje naturalizado que se extiende a orillas del Canal se convierta en un espacio ideal para realizar actividades en barco, a pie o en bicicleta.

\section{DISCURSO Y CONSTRUCCIÓN DEL OBJETO PATRIMONIAL}

El Estado, a través del ente Vías Navegables de Francia (VNF), el órgano público responsable de su explotación, evalúa los posibles costes que comportarían las obras de restauración en 145 millones de francos (20 M de euros) (Genieys y Négrier 2002). A la vista de este elevado coste parece indispensable buscar socios con los que pueda abordarse el proyecto. Las partes interesadas en su gestión (el Estado, representado por el Ministerio de Medio Ambiente y Patrimonio y VNF) oficializan el reconocimiento formal del valor patrimonial del Canal e impulsan nuevas políticas de cooperación para asegurar la perdurabilidad de la obra (Genieys y Négrier 2002). Este acuerdo pone de manifiesto que, en principio, la activación patrimonial del Canal no responde a una iniciativa local, sino a un abordaje de la cuestión desde una estructura central, con el fin de hallar financiación.

En 1991, el Informe Chapon³ , elaborado a petición del Estado, plantea una disyuntiva: crear un parque dedicado a los canales del Midi o mantener el tráfico comercial, aunque asociándolo al desarrollo del turismo fluvial (Rapport Chassel 2003). Ninguna de las opciones prospera debido al desacuerdo entre el Estado y las regiones acerca de las contribuciones financieras respectivas.

Las negociaciones, sin embargo, conducen a la idea de elaborar un Libro Blanco, que se publica en 1994. En él se realiza una doble recomendación. En primer lugar se constata un desmantelamiento progresivo del tejido social y económico local, anteriormente basado en el transporte de mercaderías (Genieys y Négrier 2002). Se alerta de que el territorio está experimentando una adaptación absolutamente desordenada a las exigencias del turismo masifica-

3 L'avenir du canal du Midi et du canal latéral à la Garonne, firmado por el ingeniero de Puentes y Caminos Jean Chapon el 15 de julio 1991.
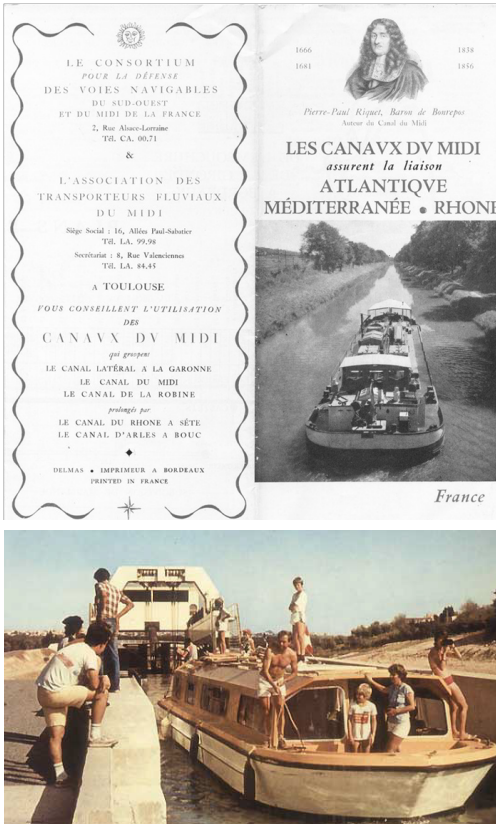

olleto promocional del "Consortium Pour La Défense des Voies Navigables Du Sud-ouest et du Midi de la France" (1950-1960). Fuente: http://bordabord.org/ Actividades recreativas en el Canal du Midi, años 1970. Fuente: http://v3.canal-du-midi.org/ 
do (Genieys y Négrier 2002), con la construcción, por ejemplo, de lagos artificiales (pantanos) y otros añadidos que adulteran el valor patrimonial del paisaje cultural del Canal. En segundo lugar, se recomienda que el ente público VNF tome el control de su gestión y mantenimiento.

En 1995 y gracias en gran medida a la iniciativa de Michel Cotte, asesor del Consejo Internacional de Monumentos y Sitios (ICOMOS ${ }^{4}$ ) y apasionado del Canal du Midi, el Estado francés (a través del Ministerio de Cultura), solicita su inscripción al Patrimonio Mundial de la Unesco. En 1996 obtiene dicho reconocimiento ${ }^{5}$. Se tienen en cuenta los valores históricos, técnicos y pintorescos del paisaje creado por el Canal. El bien clasificado tiene una superficie de 1.172 ha y su zona buffer comprende un total de 2.014 ha (Unesco 1996).

Conviene observar que la declaratoria aprobada por la Unesco ni contempla ni avala ningún proyecto territorial destinado a revalorizar el nuevo ámbito protegido. Esta inhibición es comprensible, pues la catalogación pretende básicamente respaldar la preservación. No obstante, sorprende que el detalle seguido en la descripción y la historia del monumento no se corresponda con una reseña que lo justifique. Así, por ejemplo, se establece una división del Canal en ocho tramos, pero no se explica a qué criterios responde.

La catalogación por parte de la Unesco tiene diversos efectos:

- Realización de operaciones de restauración previamente aprobadas por los servicios del Ministerio francés de Medio Ambiente y Patrimonio.

- Promoción de la función patrimonial como elemento fundamental de identidad del Canal du Midi.

- Incremento de las visitas turísticas y del desarrollo económico del lugar.

- Conversión del turismo en uno de los objetivos principales del programa de rehabilitación del Canal.

Según Genieys y Négrier (2002), un factor estratégico que contribuye al éxito de la declaración como patrimonio mundial por la Unesco es la defensa del carácter patrimonial del Canal

4 Asociación civil no gubernamental, fundada en 1965, con sede en París y ligada a la ONU a través de la Unesco. Es la responsable de proponer los bienes que reciben el título de Patrimonio Cultural de la Humanidad

5 Lo obtiene por: (i) Representar una obra maestra del genio creativo humano; (ii) Testimoniar un importante intercambio de valores humanos a lo largo de un periodo de tiempo o dentro de un área cultural, en el desarrollo de la arquitectura o tecnología, artes monumentales, urbanismo o diseño paisajístico; (iv) Ofrecer un ejemplo eminente de un tipo de edificio, conjunto arquitectónico o tecnológico o paisaje, que ilustre una etapa significativa de la historia humana y (vi) Estar directa o tangiblemente asociado con eventos o tradiciones vivas, con ideas o con creencias, con trabajos artísticos y literarios de destacada significación universal. (este criterio debe estar acompañado de otros) (Unesco 1996). 
en base al criterio del "savoir faire" y la pericia acreditada por Riquet, Vauban y los demás ingenieros que colaboraron en la ejecución del proyecto. De ese modo, la legitimación no se reduce a la catalogación como patrimonio stricto sensu, restringiendo las tareas ulteriores a una mera conservación "de monumentos estáticos en el tiempo" (Genieys y Négrier 2002), sino que se orienta hacia una puesta en valor de la acción dinámica del legado de quienes así adquieren el reconocimiento de ser "Constructores del Estado" (Bâtisseurs d'Etat ).

A pesar de que en un primer momento la modernización del Canal parece basarse en la actualización del gálibo con el fin de aumentar el tonelaje de las embarcaciones comerciales, finalmente acaba, inclinándose hacia la valorización de la dimensión patrimonial. Así, el desarrollo territorial y paisajístico del área atravesada por el Canal queda vinculado a la puesta en marcha de políticas relacionadas con el turismo fluvial y el acondicionamiento de las orillas para el uso deportivo y recreativo de los habitantes próximos. Las riberas pasan a constituir así un valor añadido. Estas nuevas dinámicas permiten la aparición de alternativas de desarrollo local que conllevan cambios en el medio social y profesional.

Según Bouneau y Lung (2006), el cambio de opción se adopta en discrepancia con la corporación de la "Gente del agua" que prefiere preservar el carácter original de la infraestructura. El diseño de la nueva funcionalidad como objeto patrimonial surge a iniciativa de las instancias ministeriales que representan al Estado, el ente VNF, así como otros actores como Michel Cotte, activos en el seno de organizaciones no gubernamentales (ICOMOS). Puede afirmarse, en consecuencia, que la puesta en valor patrimonial del Canal du Midi no surge de una iniciativa local, sino de la propuesta estatal, destinada a obtener reconocimiento para la promoción del patrimonio arquitectónico e ingenieril.

\section{DIFICULTADES DE GESTIÓN Y DE ENTENDIMIENTO ANTE EL PROYECTO DEL CA- NAL DU MIDI}

Desde el abandono de la navegación mercantil las administraciones públicas han generado diversas fórmulas de colaboración conjunta para gestionar la preservación y los usos del recurso. Asimismo, desde su inclusión en el catálogo del Patrimonio Mundial de la Unesco (1996) se han elaborado diferentes documentos destinados a definir un proyecto territorial, patrimonial y paisajístico, así como para acordar la gestión del paisaje cultural que confor- 
Fragmentación de la gestión del Canal du Midi. Fuente: elaboración propia a partir de http://gardonsnospaysagesoccitans.blogs.midilibre.com/

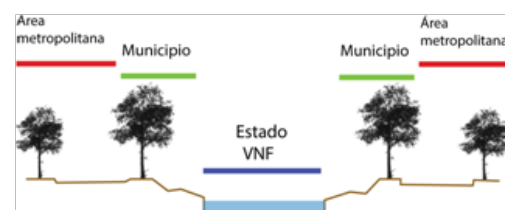

ma. Esta relativa abundancia de estudios, dictámenes y proyectos contrasta, sin embargo, con la falta de respuesta a los requerimientos de la Unesco para que se identifiquen aspectos importantes de la catalogación.

La lenta constitución de una línea de actuación y de un organismo definido de financiación y gestión revela, sin duda, la complejidad que entraña la incorporación de una infraestructura tan compleja como el Canal al legado patrimonial, en este caso de Francia. El gran volumen de documentación generada testimonia que la puesta en común no ha sido en ningún caso sencilla.

El Canal se presenta como un eje patrimonial compartido entre diferentes administraciones. VNF, gestora del canal desde 1991, es el ente estatal encargado de diseñar una estrategia global de reconversión y desarrollo para favorecer el tráfico fluvial recreativo. Actualmente continúa gestionando el recurso hídrico; esto es, asegurando la navegabilidad, realizando tareas de mantenimiento y fijando las tarifas de uso.

Desde 1988 se han concertado asimismo diversos "Contratos Estado-Región", en virtud de los cuales ambos niveles de la Administración pública se asocian en la financiación plurianual necesaria para mantener el Canal, mejorar las condiciones de acogida y la señalización, proteger el medioambiente con intervenciones sobre el paisaje y gestionar el agua y los residuos (Contrat Rég. 2008).

A partir de la incorporación al catálogo de la Unesco, se instituye un comité interregional, el "Pôle de Compétence du Canal des Deux Mers", encargado de definir una política común de puesta en valor turística del conjunto lineal y sus alrededores. Entre sus tareas figura el dar coherencia e integrar las voces divergentes sobre la gestión del Canal, así como dar publicidad a los estudios e informes realizados sobre él.

A pesar del tiempo transcurrido desde 1996, aún no se ha dado respuesta a la requisitoria de la Unesco, cuando en la misma declaratoria que cataloga el recurso, solicita que se defina la zona buffer o de amortiguación del espacio patrimonial. En la declaratoria de la Unesco (1996) se engloban por defecto los municipios atravesados por el eje, sin realizar un análisis paisajístico minucioso que tenga en cuenta los puntos de vista y las perspectivas hacia y desde la infraestructura. Estos silencios ponen sin duda de manifiesto las desavenencias y tensiones existentes entre los diferentes responsables de la gestión. Así, el ente público, VNF, se opone a una concepción museográfica, mientras que las instituciones culturales 
ministeriales abogan por una protección y clasificación más exhaustiva y pormenorizada de las partes del conjunto (Rapport Chassel 2003).

Desde el punto de vista territorial y paisajístico, el anteproyecto de 2007 (Résumé Charte Interservices 2007) resulta especialmente interesante. Se trata de un documento preliminar del que debería unificar las diferentes percepciones y criterios existentes en materia de paisaje, ordenación del territorio y urbanismo. Para ello, propone un "método de análisis único de los paisajes, un vocabulario común y argumentos coherentes con estos análisis sea cual sea el ámbito de intervención". Como indicio quizás de las dificultades de entendimiento, llama la atención el énfasis que se da a la necesidad de utilizar un "lenguaje común" que sirva para "caracterizar los cambios de usos, las problemáticas y la evolución territorial y de las funciones del Canal, así como sus consecuencias en la ordenación del territorio" (Résumé Charte Interservices 2007). Por ahora existen los siguientes instrumentos de gestión, reveladoramente no preceptivos:

- Libro de gestión sobre el conjunto objeto de catalogación. Este documento de referencia contiene un inventario de los elementos constitutivos del patrimonio (riberas, plantaciones, construcciones, caminos de sirga, equipamientos, etc.). Su principal objetivo es orientar al Estado en materia de autorizaciones, para asegurar la coherencia de las intervenciones sobre el espacio patrimonial.

- Diversos planes de gestión sectoriales o temáticos: Cahier de prescriptions architecturales et paysagères des écluses et maisons éclusières, Cahier de gestion du seuil de Naurouze y Plan de gestion des plantations.

El anteproyecto de 2007 manifiesta que se está trabajando en la elaboración de cierta Carta de Inserción paisajística del Canal du Midi. Su cometido sería definir con precisión los límites de la zona buffer y proveer directrices sobre su gestión. A la espera del documento definitivo, éste de 2007 propone diversas "Orientaciones para una muestra de diez temas representativos de las evoluciones de la zona buffer". Se trata de puntos, de carácter muy genérico, referidos al conjunto del Canal que hacen referencia a los usos y afectaciones del suelo actuales y a su compatibilidad con la zona buffer.

La definición de los límites del área de influencia tiene una importancia crucial si se tienen en cuenta dos problemas con los que se enfrenta el territorio que atraviesa el conjunto patrimonial. En primer lugar, soporta una fuerte presión urbanizadora. Aunque los paisajes agrícolas aún re- 
presentan el $85 \%$ del frente del Canal (Rapport Mission 2012), el Sureste de Francia es un territorio que reúne diversos atractivos. Sobre él intervienen las dinámicas espaciales y sociales a gran escala del eje económico y urbano del Mediterráneo occidental -la conexión entre la Península Ibérica y el Norte de Europa- y el polo industrial y científico de Toulouse. Ambos ámbitos inciden fuertemente en el territorio por donde discurre el Canal. Ello conlleva un importante desarrollo económico y un notable crecimiento demográfico, lo que a su vez comporta crecimiento urbano y periurbano. Parece lógico pensar en la delimitación de una zona de influencia clara cuando el crecimiento y la dispersión urbanos amenazan con ignorar el valor patrimonial del Canal du Midi.

Por otro lado se plantea la cuestión de la carga turística sobre un patrimonio caracterizado por una vasta longitud, pero una escasa amplitud. El aumento desmesurado de proyectos turísticos puede afectar negativamente al equilibro y la quietud de estos paisajes, características que representan precisamente los valores más buscados por los visitantes. Aunque la reconversión turística presenta un atractivo económico innegable, la existencia de unos límites y unas normas definidas de ocupación permitirían combinar los usos turísticos con el carácter apacible del paisaje del espacio patrimonial.

El mapa que acompaña la ficha de la declaratoria de la Unesco diferenciaba 8 ámbitos. Pero la tarea de identificar sectores acaba ahí. No los caracteriza, ni define objetivos para cada uno de ellos. En este sentido el informe de 2007, sin ser operacional, nos aporta lo que los autores califican de "presentación sumaria de los conjuntos paisajísticos" que permite identificar mejor los principios de ordenación de cada uno de ellos. Así, el documento distingue 10 ámbitos paisajísticos ${ }^{6}$

La extensión de cada tramo oscila entre 17 y $43 \mathrm{~km}$. Cada uno de los ámbitos paisajísticos toma el nombre de la región natural donde se ubica (Lauragués), se define por sus características geográficas (valle, llanura, laguna, etc.), o bien por el uso del suelo y el grado de urbanización (periurbano o rural). Cada ámbito se completa con una descripción sintética y eficaz de los elementos bióticos, abióticos y culturales que caracterizan el paisaje, un esquema de localización y un listado de los términos municipales comprendidos en el ámbito. La ficha de 2007 incluye la proporción de fachadas urbanas sobre el eje del canal para cada uno de los conjuntos paisajísticos.

61. Tramo Lauragués /Periurbano; 2. Tramo Lauragués Rural; 3. Lauragués; 4. Montaña Negra; 5. Valle del Lauragués; 6. Valle del Fresquel; 7. Valle del Aude; 8. Llanura del Languedoc; 9. Llanura Litoral; 10. Lagunas y albuferas. 
Contiene también formulaciones notablemente precisas sobre la "transmisión del patrimonio". Así, distingue entre elementos de carácter atemporal o "constantes del Canal" (les invariants) y las "novedades" que atestiguan su supervivencia (recogidos en el cuadro de la página siguiente).

El concepto de patrimonio territorial atiende sobre todo a los denominados "elementos constantes". Los objetivos perseguidos son varios: mantener la escala de la obra y el sistema hidráulico, desarrollar las políticas de protección pertinentes, así como poner en valor los paisajes y, por último, adaptar las competencias del Estado sobre el Canal.

Además, la futura Carta de inserción debe desarrollar los siguientes aspectos: 1) valor patrimonial a escala territorial del Canal; 2) el Canal como parque lineal; 3) el Canal como zona de exclusión de grandes intervenciones; y 4) capacidad de acogida de los parajes y construcciones del Canal.

\begin{tabular}{|l|}
\hline Elementos constantes \\
\hline Trazado y dominio del agua \\
Escala de la obra \\
Conjunto de construcciones y funciones \\
Dimensión poética \\
\hline Objetivos \\
\hline a.Mantener el trazado dictado por el relieve alejado de los núcleos urbanos \\
b.Mantener la percepción a gran escala de largas distancias y secuencias, así como la falta de refe- \\
rencias geográficas y temporales \\
c.Mantener la coherencia entre las obras del canal y la función para la que se construyeron \\
d.Transmitir la dimensión poética \\
\hline
\end{tabular}

\begin{tabular}{|l|}
\hline Novedades \\
\hline Nuevos usos \\
Una nueva mirada sobre el medio ambiente \\
Aumento de la frecuentación del Canal \\
\hline Objetivos \\
\hline $\begin{array}{l}\text { a. Conciliar las nuevas funciones turísticas, sociales, culturales y residenciales con el patrimonio en } \\
\text { sentido amplio, sin desnaturalizarlo } \\
\text { b. Vincular el valor histórico, arqueológico y arquitectural a la sociedad y actividades contemporáneas } \\
\text { c. Adaptar la frecuentación y el desarrollo económico a las características "constantes" del canal, sin } \\
\text { permitir que sometan la evolución del Canal y su zona buffer }\end{array}$ \\
\hline
\end{tabular}

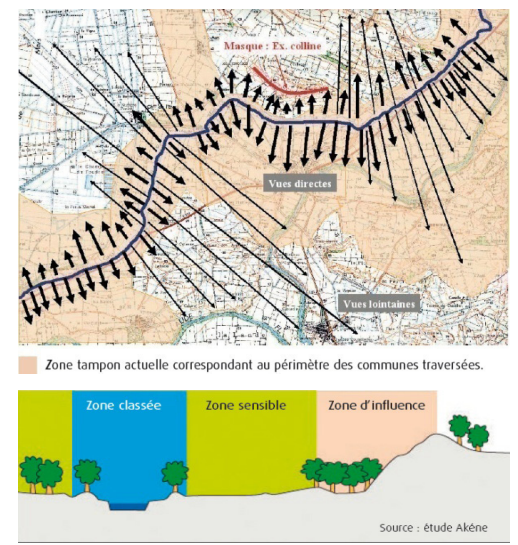

Zona buffer del Canal du Midi. En beige zona buffer actual correspondiente a los límites de los municipios atravesados. Clasificación de la zona buffer en tres subzonas. Fuente: (Classement 2012 y SCOT 2012) 


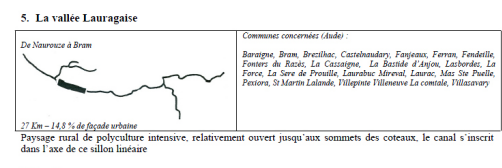

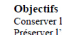

Conjunto paisajístico del valle del Lauragués. Fuente: (Résumé Charte Interservices 2007)
Desde el punto de vista administrativo, el canal constituye un lazo entre diversos planos de la organización civil: 104 municipios, cuatro departamentos, dos regiones y, en definitiva, el estado que ha velado por preservar su legado arquitectónico. Desde el punto de vista del paisaje, el Canal une ámbitos tan heterogéneos como: el litoral mediterráneo, la llanura del Languedoc, regiones de policultivos y áreas urbanas o periurbanas.

El parque lineal se concibe como una especie de columna vertebral para la ordenación del territorio, capaz a la vez de proteger los usos agrícolas, reforzar el vínculo de interacción entre los diferentes tramos y de las diversas perspectivas que se desee invocar. Recurrir a un parque lineal proporciona una nueva perspectiva desde la cual, la zona de amortiguación que se delimite puede contrapesar la presión que resulta de los crecimientos urbanos. Debe permitir asimismo el crear un espacio protegido de distensión que favorezca la calidad de vida de los habitantes próximos.

La estrategia de instaurar una zona de exclusión de grandes intervenciones tiene como objetivo proteger la escala y los ritmos de los paisajes que jalonan el eje patrimonial Se desea proteger así el carácter específico de estos paisajes y de su zona de influencia, evitando la presencia de equipamientos e infraestructuras de grandes dimensiones. Finalmente, se pretende evaluar de manera sostenible la capacidad de carga de los parajes y de las obras para evitar una sobrecarga de visitantes que desvirtúe el carácter apacible de la infraestructura y sus paisajes.

La dimensión interregional del Canal parece constituir, con todo, una traba suplementaria a la voluntad de desarrollar un proyecto paisajístico y patrimonial en torno al mismo; del mismo modo que lo es la concurrencia de organismos y servicios estatales con ámbitos de actuación e incluso objetivos no contrapuestos, pero sí altamente diferenciados. Sea como fuere, lo cierto es que aún no existe ningún proyecto de ordenación que fomente el anclaje territorial como dimensión central del plan.

Un ejemplo de tensión y disonancia se advierte en la armonización entre las administraciones superiores y la municipal. A escala municipal las estrategias de valorización patrimonial y paisajística y los proyectos de reconversión económica van generalmente aparejados con la puesta en marcha de programas y operaciones turísticas. Sin embargo, su incorporación al circuito patrimonial no obtiene una compensación inmediata; cuando resulta evidente 
que las restricciones urbanísticas aumentan en la zona de influencia del Canal. En el caso de proyectos como el puerto d'Homps o de Agde nos hallamos ante situaciones free-rider donde el desarrollo local queda desvinculado de una visión de conjunto.

\section{USOS ACTUALES A ESCALA LOCAL Y EDIFICATORIA}

Los informes y documentos consultados coinciden en destacar que desde finales de los años 1980 el Canal du Midi cumple dos funciones: una preexistente, la irrigación de 40.000 ha de tierras agrícolas y una nueva, el transporte fluvial recreativo que genera un tránsito de más de 1.000 embarcaciones entre el Atlántico y el Mediterráneo cada año (Rapport Mission 2012). Sin embargo, existe otro uso reciente que no debe desdeñarse aunque los ingresos directos que genera sean difíciles de calcular. Se trata del uso deportivo y recreativo realizado a sus orillas. Esto viene a coincidir fragmentariamente con los esfuerzos desplegados por quienes han impulsado la catalogación patrimonial, con la particularidad de que arranca de iniciativas locales. Nos referimos a la reivindicación de las orillas de los cursos de agua para usos recreativos.

Desde los años 1970 y paralelamente a la disminución del tráfico mercantil, se desarrollan campañas acordes con el nuevo paradigma ecológico y de puesta en valor de la naturaleza como recurso para suscitar una mejor calidad de vida. La campaña "Sport pour tous" reclama el uso del Canal para la práctica de deportes al aire libre (Bouneau y Lung 2006). En 1974 se organiza en Toulouse un Comité en defensa de las orillas del otro curso de agua que atraviesa la ciudad (el río Garona), para oponerse a un proyecto municipal de vías rápidas en las orillas. La iniciativa constituye un interesante testimonio de la consideración ecologista en el entorno urbano y pone sobre la mesa la idea de "realizar un complejo de ocio [...] que proporcione a los habitantes de Toulouse un lugar de paseo". El mismo año, un consejero municipal de Labège, municipio del área metropolitana de Toulouse, propone el acondicionamiento de un carril-bici en las orillas del Canal que califica de "lugares casi abandonados". Tras recoger 35.000 firmas a favor, el proyecto logra imponerse y la pista empieza a construirse en 1978.

Ese tipo de demandas crea unas expectativas de uso de las orillas que aparentemente enturbian la diafanidad de usos del Canal (mercantil, agrícola o turístico). A su vez, permite plantear qué incidencia puede tener la naturaleza de los usos, dependiendo de si se trata 


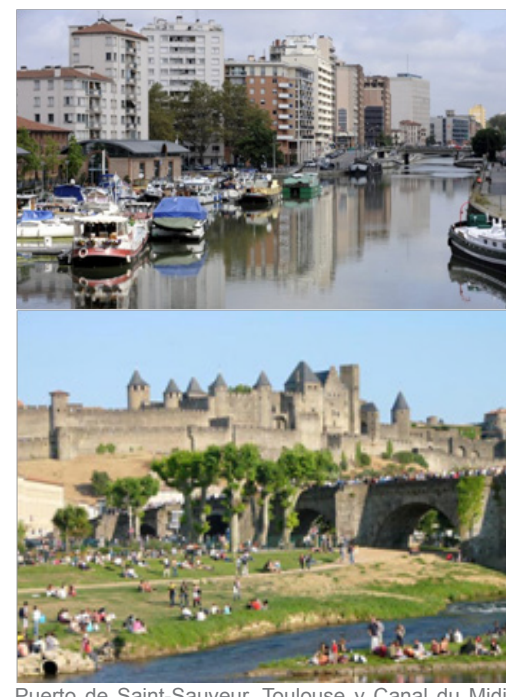

Puerto de Saint-Sauveur, Toulouse y Canal du Midi por Carcassonne. Fuente: http://www.ladepeche.fr/ y www.toursud.com de usos artificiales (inducidos y trasplantables a otro lugar) o naturales (derivados de las dinámicas preexistentes). En efecto, con la llegada de ciclistas, paseantes y corredores, el estatuto del espacio patrimonial pasa de artificial, curso de agua creado para el trabajo agrícola y mercantil, a espacio público natural ${ }^{7}$, ajardinado, de proximidad, de lo cual a su vez se deriva otra implicación para los municipios: su mantenimiento. El paso artificial a natural viene secundado por nuevos actores que solicitan la naturalización de una infraestructura, por esencia artificial, para desarrollar sus actividades de ocio.

Cabe preguntarse si la espontaneidad de la iniciativa vecinal guarda algún tipo de correspondencia con la parsimonia de los organismos públicos ante las consecuencias que debería tener la catalogación del Canal por la Unesco. Sin embargo, es ilustrativo reparar en el estado actual de sus orillas, 35 años después de esa demanda vecinal.

Actualmente en Toulouse existe un carril bici (vía verde) que discurre a lo largo de $5 \mathrm{~km}$, por un camino segregado de 3 metros de anchura desde el lugar denominado Ponts Jumeaux (situado en el extremo occidental donde confluyen el Canal du Midi y el río Garona). Fue financiado por el municipio. Este tramo de $5 \mathrm{~km}$ queda comprendido en la vía verde acondicionada y asfaltada de $50 \mathrm{~km}$ que continúa hasta la esclusa de l'Océan, la quinceava del Canal. Constituye la primera sección de un recorrido que finaliza en el puerto mediterráneo de Sète. Sin embargo, a partir de la esclusa de l'Océan (Seuil de Naurouze), la vía aún no está acondicionada. Se da la circunstancia que el siguiente nivel administrativo (el departamento de la Haute-Garonne) ha recogido a su vez parte de las iniciativas recreativo-deportivas financiando el tramo de $45 \mathrm{~km}$ hasta la esclusa del Océan. Desde 2006 se realizan tareas de mantenimiento cada año para reparar la pista con una técnica de emulsión al frío (grave émulsion à froid) que produce un material más acorde con las tonalidades del paisaje [Af3 2013].

La vía verde entre Toulouse y la esclusa $n^{\circ} 15$ discurre a la sombra de los plátanos y permite descubrir el Canal, sus obras y los pueblos del área del Lauragais. Asocia la función patrimonial a una función deportiva. Se han habilitado varias áreas de descanso con mesas de picnic y lavabos aproximadamente cada $10 \mathrm{~km}$ que actúan como nodos a lo largo del camino. En las intersecciones con las carreteras no hay "control físico de acceso", facilitándose así el acceso de todo tipo de usuarios no motorizados y mejorando la fluidez de un itinerario

7 La definición de natural se atribuye en oposición al espacio urbanizado. 
altamente concurrido. En 2010 se instalan obstáculos para evitar el estacionamiento de vehículos ante puentes y esclusas. El objetivo es que esta vía actualmente acondicionada a lo largo de $50 \mathrm{~km}$ de Canal, quede integrada en el proyecto de "Vía verde de los Dos Mares" (Voie Verte des Deux Mers) que prevé conectar el Atlántico y el Mediterráneo.

En su globalidad el Canal du Midi puede considerarse un monumento paisajístico provisto de importantes elementos patrimoniales. Su configuración ha modelado un gran jardín a escala territorial compuesto por una cinta hídrica que malla el territorio, circundada por dos suaves pendientes cubiertas de hierba a ambos lados de las riberas y separado de los territorios colindantes por alineaciones plantadas ${ }^{8}$ que crean un ambiente íntimo, protegido y ajeno a lo que le circunda.

La reafirmación del itinerario deportivo y recreativo a orillas del Canal puede convertirse en elemento estructurador y en una estrategia clave dentro del proyecto territorial de parque lineal. Permitiría impulsar una actividad endógena, que los residentes pueden disfrutar. De ese modo se lograría un contrapunto que compense y enjugue una excesiva masificación turística. Así se podría evitar que la función turística acaparase y desnaturalizase este paisaje cultural.

\section{CONCLUSIONES Y VALORACIONES}

El Canal du Midi es el resultado de una obra humana que ha desencadenado cambios en el paisaje por el que discurre. En tanto que paisaje cultural, nos muestra la evolución de usos vinculados a una infraestructura hidráulica. Estas mutaciones de función vienen amparadas por cambios de carácter más global en la sociedad y provocan en primera instancia la pérdida de una identidad pero también la ocasión de generar nuevas identidades para el territorio.

Si bien a lo largo de sus tres siglos de existencia hay un uso -el agrícola, de regadío- que se ha preservado, los cambios tecnológicos han motivado que se abandone el uso primordial

8 Estas alineaciones vegetales de Platanus acerifolia que sellan el conjunto se ven actualmente diezmadas por una epidemia de antragnosis. Una de las principales preocupaciones de las administraciones y actores implicados en la gestión y puesta en valor del Canal, son las posibles consecuencias paisajísticas de la epidemia, así como los costes que conlleve la replantación de las alineaciones de plátanos. Prueba de ello es el documento titulado “Le Canal du Midi, un chef d'oeuvre en péril" publicado por la Cámara de Comercio e Industria de Béziers (Canal Péril 2012).
Usos y paisaje del Canal du Midi por el Languedoc Roussillon. Fuentes: http://www.canalmidi.com/ y http://www.randovelo.fr/

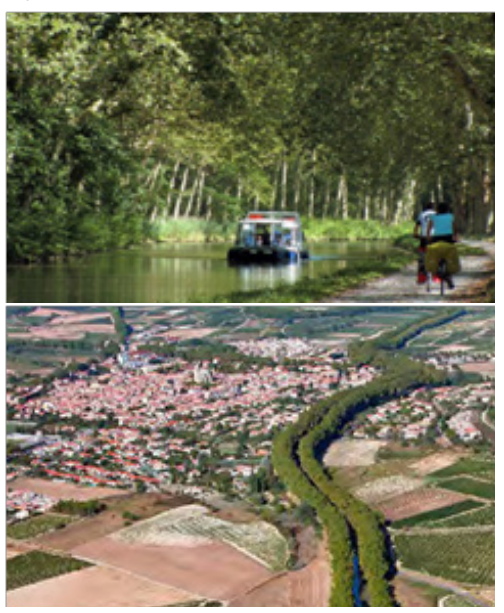




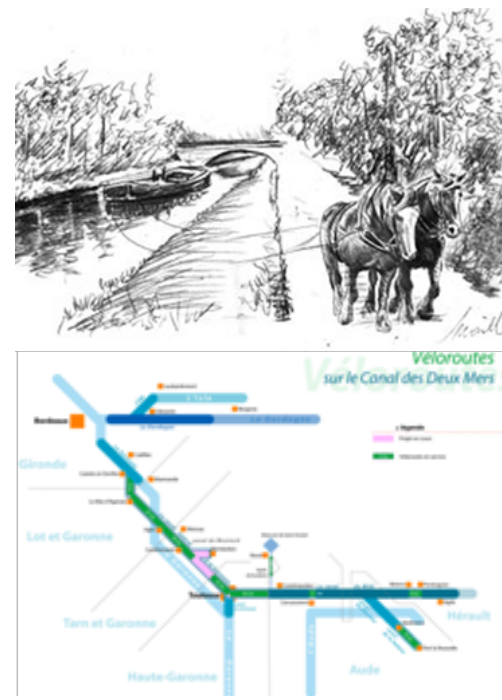

Antiguo camino de sirga y plan esquemático de la red de carriles bici (2008). Fuente: www.sudouest.vnf.fr para el que se construyó, el de transporte, pues no puede competir ni con el ferrocarril ni con el transporte por carretera, si se quiere conservar su valor patrimonial. Por otro lado, la sociedad ha evolucionado hacia una nueva cultura de la sostenibilidad y hacia una ampliación del ocio y las actividades recreativas, lo que ha permitido descubrir utilidades diferentes en el tramo de los 240 km que componen la vertiente mediterránea del Canal de los dos Mares.

Las transformaciones conllevan nuevas perspectivas para el territorio cruzado por el Canal: a pequeña escala se dan nuevas demandas de planificación y de gestión; a mayor escala, el espacio requiere nuevos acondicionamientos en sintonía con los usos actuales y los potenciales. Asimismo, el mantenimiento de un canal necesita que discurra agua. Por lo tanto, sin navegación mercante, la recreativa aparece casi como esencial para mantener la herencia patrimonial. Con todo, se plantea una cuestión de costes directos e indirectos que a todas luces dificulta una toma de decisión. Entre los costes directos se encuentra el mantenimiento de la infraestructura, pero también el de su ámbito más o menos inmediato. Entre los indirectos, la aceptación de una regulación que condicione unos beneficios económicos más o menos rápidos, por ejemplo, de las promotoras inmobiliarias y más indirectamente aún, de los municipios.

Las tensiones que se generan al respecto pueden resumirse trayendo a colación la cuestión de si las propuestas responden a iniciativas naturales y auténticas, o bien a iniciativas artificiales. La respuesta, sin duda, no es sencilla. Por una parte, puede considerarse auténtico mantener los hábitos de una población cuyo medio de subsistencia entra en crisis. Bouneau y Lung (2006) insisten en que la población más vinculada al Canal, los que trabajaron en él y por tanto, son portadores de parte de la memoria de esta obra hidráulica, se muestran reticentes a la conversión. Esto nos lleva a pensar que la función turística pudo ser sobreimpuesta, con el fin de poner en valor un curso de agua artificial acondicionado en el siglo XVII.

Por otra parte, si por auténtico se entiende aquello que aporta un beneficio, hace falta sin duda una panorámica muy amplia para advertir las ventajas que comportaría invertir en la conservación y la puesta en valor de este extenso tramo de Canal. Se trataría de beneficios culturales (conservación del patrimonio), sociales (cultura del ocio y del deporte), ambientales (equilibrio ecológico en zona de cruce de tráfico) e incluso lucrativos (salvaguarda de un lugar apacible y a la vez bien comunicado). Quizá la necesidad de una perspectiva amplia explique no sólo las líneas de actuación que se han adoptado, sino también los titubeos y 
las dificultades para coordinarse con iniciativas más modestas. Por una parte se cuenta con la intervención de estructuras estatales y supraestatales (ministerios, VNF, la gestora de las vías navegables, pero también un organismo internacional como la Unesco, o las asociaciones de promoción del turismo, no ajenas seguramente a la industria hotelera). Por otra, se registran iniciativas más o menos espontáneas.

La intervención de todas ellas testimonia un giro hacia una puesta en valor patrimonial, pilotado desde las más altas instancias del país. Esta aproximación desde arriba legitima el valor patrimonial de la obra de ingeniería invocando su contribución a la categoría de los "Constructores del Estado". Del mismo modo, y en consonancia con la práctica de una administración pública desarrollista y centralizada, impulsa una visión global del proyecto y la creación de instituciones como el "Pôle de Compétence" para dar una sola voz a los diferentes actores regionales.

Por otro lado, habrían las iniciativas locales y municipales, no siempre dirigidas al propio Canal du Midi, pero reconducibles hacia esa vía de agua. Se trata de las iniciativas que se han opuesto a la destrucción del paisaje ribereño para construir vías para el tráfico de vehículos de motor y han defendido su correspondiente salvaguarda como pistas ciclistas o de sendero.

Entre ambos tipos de iniciativas no se ha producido por el momento ningún encuentro. Seguramente por esa razón las estatales y supraestatales de carácter proteccionista se han movido en una notable inconcreción. La declaratoria aprobada por la Unesco no incluye ninguna estrategia territorial de puesta en valor del patrimonio. En el caso del Canal del Midi este reconocimiento llega solo cinco años después de las primeras reflexiones oficiales sobre el cambio de usos y de base económica, pero no se han alcanzado aún grandes logros.

La dificultad de llegar a acuerdos territoriales se traduce en la falta de una delimitación clara de la zona de amortiguación, diecisiete años después de su inclusión en el listado de Patrimonio Mundial. En el 2007 se redacta un anteproyecto que siete años más tarde no hemos visto aun formalizado. El trabajo de definición de paisajes y de delimitación de tramos realizado por este anteproyecto constituye un paso decidido en el proceso de busca de un proyecto territorial para el Canal du Midi. Aunque el frente del Canal se presente como un elemento a considerar en su globalidad, los paisajes que atraviesa son diversos. Las ne- 
cesidades de planificación de cada uno de estos territorios también varían: las normativas, la frecuentación o los usos son diferentes en un entorno urbano, que en uno periurbano, agrícola o silvícola.

Ante esa falta de encuentro no debe sorprender que los costes de replantación de las alineaciones de plátanos diezmados por una epidemia hayan eclipsado, por ejemplo, la preocupación por definir un área de amortiguación. Sería probablemente la estrategia más viable para frenar la alta presión urbanizadora de los entornos del Canal.

Otra cuestión a tener en cuenta es la ampliación de la participación local. Sería interesante conocer los puntos de vista de los habitantes y de las personas que frecuentan el Canal a la hora de determinar los objetivos y las necesidades de los paisajes por los que discurre.

La paradoja resulta de la constatación que el anclaje territorial del Canal no es la dimensión central del proyecto aunque éste sea llevado a cabo por instituciones regionales. Resulta vano e improductivo seguir concibiéndolo como motor desde una perspectiva de conservación del patrimonio simplista y resistiéndose a los estímulos exteriores.

Lo interesante sería que el Canal se concibiera como una ventaja o incluso, como el activo principal que sirviese para complementar la mejora de la calidad urbanística y el desarrollo económico de las regiones que atraviesa. Esta concepción más abierta apostaría por la conservación de las obras inventariadas pero también por la puesta en valor de las calidades paisajísticas y el acondicionamiento para nuevos usos de sus orillas. Por lo tanto, no se trata sólo de valorar, sino de articular los valores de las diferentes obras (nodos) que lo jalonan, vinculándolos entre sí a través de las vías de servicio que sirven de itinerario. Al tratarse de una franja estrecha de tres metros es importante que las entradas y salidas a estas vías sean numerosas y estén bien repartidas según la frecuentación de cada tramo.

La estrategia de formalizar el uso de proximidad así como un turismo deportivo que visite los parajes, pero que también realice estancias en los pueblos que bordean el eje patrimonial permitiría fomentar una actividad propia y permanente. Estos usos tendrían, si se quiere, un carácter más genuino y permitirían fomentar y poner en valor el paisaje cultural del conjunto. 


\section{BIBLIOGRAFÍA}

ADGÉ, M., (1992), "Le Canal du Midi ou la jonction des mers en Languedoc", Mappemonde n¹. 5 págs. Consultado el 12/2013 en: http://www.mgm.fr/PUB/Mappemonde/M192/CANAL.pdf

[Af3 2013] Les véloroutes et voies vertes de France. Association française de développement de véloroutes et voies vertes de France. Consultado el 12/2013 en: http://www.af3v. org/-Les-VVV-de-France-.html

BONNERANDI, E. , (2005), "Le recours au patrimoine, modèleculturel pour le territoire ?", Géocarrefour vol. 80/2. 14 págs. Consultado el 12/2013 en: http://geocarrefour.revues. org/991

BOUNEAU, C. ; LUNG, Y. (2006). Les territoires de l'innovation, espaces de conflits. Bordeaux: Maison Sciences de l'Homme d'Aquitaine, France.

Canal Péril (2012). “Le Canal du Midi, un chef d'oeuvre en péril. Volet 1 : Etat des faiblesses et enjeux liés au Canal du Midi”, CCI Béziers Saint-Pons, Service Tourisme. Consultado el 12/2013 en: http://www.beziers.cci.fr/files/cci_bezier/etude-environnementale-ccib.pdf

Classement (2012),"Classement des abords du Canal du Midi. Pour une gestion durable d'un patrimoine exceptionnel". Obra colectiva: Directions Régionales de l'Environnement de l'Aménagement et du Logement Midi-Pyrénées et Languedoc-Roussillon y VNF. Consultado el 12/2013 en: http://www.midi-pyrenees.developpement-durable.gouv.fr/IMG/pdf/plaquette-classement-BAT_cle516197.pdf

Contrat Rég. (2008), " Contrat régional spécifique pour un projet de développement et de valorisation économique du Canal des Deux-Mers et des territoires riverains" .Préfet et Président de Région Midi-Pyrénées, Voies Navigables de France.

Fiche (2007), " Site Classé Languedoc-Roussillon: Canal du Midi”. Direction Régionale de l'Environnement de l'Aménagement et du Logement Languedoc-Roussillon.

GENIEYS y NÉGRIER (2002) en NÉGRIER, E. et al. (2002). Patrimoine culturel et décentralisation. Une étude en Languedoc-Roussillon. Paris : L'Harmattan. Págs. 199-228.

Haute Garonne (2008) Porteur à connaissance ,"Le Canal du Midi, Comment le valoriser et 
le préserver". Consultado el 12/2013 en: http://www.pac.haute-garonne.equipement.gouv.fr/ IMG/pdf/plaquette_canal_cle2aed96.pdf

[Peniche 2013] Consultado el 12/2013 en: http://www.peniche.com/2sommaire2.htm

Rapport Chassel (2003), "Canal du Midi”, Inspection générale de Conseil général des Ponts et Chaussées l'Architecture et du Patrimoine rapport n²003-0084-01. Ministère de l'Ecologie et du Développement Durable, Ministère de la Culture et de la Communication, Ministère de l'Equipement, des Transports, du Logement, du Tourisme et de la Mer . Consultado en 2013 en: http://www.ladocumentationfrancaise.fr/var/storage/rapports-publics/054000031/0000. pdf

Rapport Mission (2012) "Une ambition légitime pour le canal du Midi et le canal des Deux Mers", La documentation française. Consultado en 013 en: http://www.ladocumentationfrancaise.fr/var/storage/rapports-publics/124000315/0000.pdf

Résumé Charte Interservices (2007),"Charte interservices Relative à l'insertion paysagère et architecturale du Canal du Midi -Document de Référence pour la zone sous influence du Canal du Midi (Résumé)".Maître d'ouvrage: Préfet de la Région Midi-Pyrénées; Préfet de la Haute-Garonne, cordonnateur pour le Canal des Deux-Mers; Pôle de Compétence de l'Etat pour le Canal du Midi. Consultado el 12/2013 en: http://www.ladocumentationfrancaise.fr/ var/storage/rapports-publics/054000031/0000.pdf

SCOT (2012) "Schéma de Cohérence Territoriale Syndicat Mixte du Pays Lauragais". Consultado el 12/2013 en: http://www.payslauragais.com/scot/acceuil.htm

Unesco (1996) “World Heritage List: Le Canal du Midi”. Consultado el 12/2013 en: http://whc. unesco.org/fr/list/770/

Unesco (2005)," Etat de conservation des biens du patrimoine mondial en Europe, France, Canal du Midi". Consultado el 12/2013 en: http://whc.unesco.org/fr/list/770/

Vías Navegables de Francia (VNF), Consultado el 12/2013 en: http://www.vnf.fr/vnf/home. vnf?action=vnf

[W_Canals 2013] World Canals, consultado el 12/2013 en : http://www.worldcanals.com/ francais/france.html 